\title{
GRAVAI O BURIL NOS PÁTRIOS ANAIS DO VOSSO PODER OU \#VAIPRACINCINNATI
}

José Roberto Schneedorf ${ }^{1}$

Resumo: As três décadas mais recentes dos extremismos ideológicos e da celebrização instantânea são relacionadas, neste artigo, a partir da sucessão dos acontecimentos expositivos que as representam: de uma emblemática individual de Robert Mapplethorpe, The perfect moment, em 1990, diversos museus e galerias brasileiros herdam e sequenciam, nos dois últimos anos, os antagonismos das guerras culturais

Palavras-chave: resistência, autoficção, sexualidade, AIDS

\section{ENGRAVE THE CHISEL ON THE FATHERLAND'S ANNALS OF YOUR POWER OR \#GOTOCINCINNATI}

Abstract: The three last decades of ideological polarities and instant celebrity find one and the other related and chained, in this article, by their art exhibition symbolisms: since The perfect moment, Robert Mapplethorpe 1990's opening, up to the last two years, when several Brazilian museums and galleries inherit and have sequenced the antagonisms of cultural wars

Keywords: resistance, self-fiction, sexuality, AIDS

1 Professor da Escola Guignard da Universidade do Estado de Minas Gerais; Doutorando da Escola de Belas Artes da Universidade Federal de Minas Gerais. 
Eles até podem te matar, mas te comer é juridicamente meio complicadinho. DAVID FOSTER WALLACE

\section{B.O.}

Em três de setembro de 2019, por decisão da presidente da Casa, Mônica Leal, a Câmara Municipal de Porto Alegre cancelou a exposição Independência em risco, composta de desenhos, cartuns e charges do coletivo Grafar (Grafistas Associados do Rio Grande do Sul), que fora inaugurada no dia anterior e ficaria exposta até o dia dezenove do mesmo mês, na mesma Câmara. Veículos expressivos e reflexivos costumeiros das imprensas ocidentais, cartuns e charges atendem a uma plástica de enfrentamento político historicamente provecta, que através do humor sobreviveu e resistiu a ditaduras militares - e fomentou seus fechos. Dos regimes e das motivações para o cancelamento, certas charges foram consideradas especialmente ofensivas aos presidentes em exercício do Brasil e dos Estados Unidos da América, juntos ou separadamente.

Também em Porto Alegre, uma cerâmica sem título de 2019, de autoria do porto-alegrense David Ceccon, foi removida da individual do artista, BIO-I, antes mesmo da inauguração da mostra, em julho desse mesmo ano, na Pinacoteca Aldo Locatelli, localizada no Paço Municipal, sede da prefeitura. Ante a apresentação prévia do seu projeto expositivo, que reúne a produção desenvolvida durante residência na França no ano anterior, no Centre Intermondes de La Rochelle, a coordenação da Pinacoteca já se posicionara pela dedução de quatro das obras, convidando o artista a retirá-las da montagem, em razão da inadequação à frequência executiva e à irrestrição de idade do espaço. Ceccon insistiu em mantê-las, e a negociação resultou na extração tardia de apenas uma delas, que junta e cruza em si, a um só tempo, as referências antropomórficas ao pênis e à vagina: gênero, orientação e corpo em pauta, sempre eles no centro dos abates plásticos. Da extração, restou o prego na parede, no qual um visitante colou a palavra 'censurado'. Por tempo suficiente, lá ficou.

Mais uma vez em Porto Alegre, em dez de setembro de 2017, encerrouse precocemente, no espaço Santander Cultural, a coletiva Queermuseu: 
cartografias da diferença na arte brasileira, pressionada por acusações de profanação religiosa direcionadas à tela de 1996 do também portoalegrense Fernando Baril, Cruzando Jesus Cristo com deusa Schiva, com o ambíguo amparo do artigo 208 do Código Penal, que tipifica como crime "vilipendiar publicamente ato ou objeto de culto religioso"2. Somem-se congêneres acusações de apologia à zoofilia, apontadas para o óleo de 1994, Cena de Interior II, da carioca Adriana Varejão. Multipliquem-se em acusações de apologia à pedofilia, inculpadas ao todo expositivo, com certa predileção acriminante às mistas da fortalezense Bia Leite, Travesti da lambada e deusa das águas e Adriano Bafônico e Luiz França She-há, ambas de 2013. Note-se que as peças dos dois primeiros, Baril e Varejão, aniversariavam mais de duas décadas de sua produção. O então Secretário de Cultura de Belo Horizonte, Juca Ferreira, foi sondado por um gestor cultural próximo à curadoria do evento, sobre a alternativa de uma reabertura nessa capital, sobrevida descartada pelo prefeito Alexandre Kalil.

Em outubro do mesmo 2017, no MAM (Museu de Arte Moderna) de São Paulo, a abertura da trigésima quinta mostra Panorama da Arte Brasileira contou com a desafetada nudez do fluminense Wagner Schwartz, em sua performance La Bête, que consentia o toque no inerte de seu corpo como uma forma de manuseio referente aos dobráveis Bichos, série de junturas escultóricas iniciada em 1960 pela neoconcretista belohorizontina Lygia Clark. Troque-se as dobradiças da última pelas articulações corporais do primeiro, tendo em conta o repouso proposital, de tônus bailarino, do corpo do artista, que já apresentara o mesmo trabalho em dez ocasiões anteriores, sem maiores repercussões. Um vídeo alastrado em rede transmite a cena de dois desses toques, coprotagonizados por um menor e pelo adulto responsável que o acompanhava, sua mãe.

Dias após a performance uma turba enfurecida, liderada por certo exator pornô em busca de fama requentada, invadiu o MAM e agrediu funcionários novamente acusando a instituição de incitar pedofilia. ${ }^{3}$

2 REPÚBLICA FEDERATIVA DO BRASIL. Código penal. Brasília: Senado Federal, Coordenação de Edições Técnicas, 2017, p. 84.

${ }^{3}$ LABRA, Daniela apud DUARTE, Luisa (Org.). Arte, censura e liberdade: reflexões à luz do presente. Rio de Janeiro: Cobogó, 2018, p. 49. 
A turba, digitalizada em patrulha extremista e ancorada em evangelismos, amplificou um linchamento igualmente digital ao artista, brutalizando ameaças de morte até ao seu ir-e-vir rueiro, que culminou em forçoso depoimento na $4^{a}$ Delegacia de Polícia de Repressão à Pedofilia, da Policia Civil paulista; bem como noutro, somado aos dos curadores e da mãe da criança, na CPI dos Maus-Tratos, uma Comissão Parlamentar de Inquérito do Senado Federal. E ainda na abertura de sindicância no Ministério Público de São Paulo, posteriormente arquivada após acordo junto ao MAM, comprometendo-se este a práticas coibitivas, especialmente voltadas ao cerceamento etário de suas audiências.

A querela do septuagenário MAM repercutiu no septuagenário MASP (Museu de Arte de São Paulo), que restringiu para maiores de dezoito anos a classificação etária da exposição que abriria no vigésimo dia do mês seguinte, outubro de 2017: Histórias da Sexualidade, concebida desde 2015, e a partir dali depurada, pelos curadores Adriano Pedrosa, diretor artístico, Lilia Schwarcz, curadora adjunta de histórias, Pablo León de la Barra, curador adjunto de arte latino-americana, e Camila Bechelany, curadora assistente. A presença de menores de idade, vetada pela primeira vez nos setenta e dois anos da instituição, ondeou artistas às suas portas na véspera da abertura, protestando a censura e testificando o apoio à integridade da seleção curatorial.

A bem, rendeu: em novembro, a entrada voltou a ser permitida, se acompanhada de responsáveis. E a mal, também rendeu: a ideada itinerância descarrilou antes da parada seguinte, no MAR (Museu de Arte do Rio) do centro da capital fluminense. O mesmo MAR que também sentiu depois, em 2019, um surdo encurtamento da temporada da insubmissa Quem não luta tá morto - arte, utopia, democracia, panorâmica que abriu em quinze de setembro de 2018 com curadoria do recifence Moacir dos Anjos, dando seguimento à sua década de programas culturais e exposições artísticas de patente cunho político, iniciada em 2009 no Projeto Política da Arte, na também recifence Fundação João Nabuco. Do encerramento cronogramado para o dia vinte e cinco de maio de 2019, a mostra do MAR quitou-se com quase dois meses de antecipação, a trinta e um de março, com alarido da classe inversamente proporcional à mudez jornalística, conduta que se encontra em exponenciação, particularmente nesse último par de anos, quando duas raias antagônicas solaparam no país a pluridade ideológica, atraindo para si os extratos intermediários.

No mesmo outubro do mesmo 2017 de La Bête e de Histórias da Sexualidade, o Palácio das Artes da capital mineira inaugurou a coletiva 
da terceira edição do Projeto ArteMinas, que melhor simetriza-se em quatro individuais simultâneas, setorizadas em suas dependências. $\mathrm{Na}$ maior delas, a Grande Galeria Alberto da Veiga Guignard, a póstuma do prematuramente falecido belo-horizontino Pedro Moraleida Bernardes, Faça você mesmo a sua Capela Sistina, propensa ela e propenso ele ao caráter iconoclasta, propenso esse a frontear religião e sexo. Outra vez, as malsinações de pedofilia - novamente ela, procurada em toda parte e blasfêmia de parte de religiosos e direitistas, que regularmente entendem a si como continentes da unificação desses predicados - em que pese, em verdade, o antagonismo semântico -, em ataques digitais e protestos rueiros constrangendo pelo cancelamento da mostra. Outra vez, a contraparte de similares medidas públicas, por parte de artistas (locais, regionais e nacionais) e de esquerdistas - em que pese, aí sim, a harmonia entre os dois últimos vocativos. Outra vez, resultou na perquirição do prefeito Alexandre Kalil, sancionando:

A obra é absolutamente normal e não acredito que nenhum homem do século $X X I$ se choque de verdade com o que viu aqui. E nem se fosse mais chocante do que é, porque não é, aqui é o lugar disso. ${ }^{4}$

A observação veiculou-se pelas mais diversas mídias e replicou-se no Manifesto mineiro pela cultura e contra a censura, redigido no mesmo mês por Juca Ferreira e divulgado em seus perfis em redes sociais, em alinho com outros de mesmo teor que se promulgaram em diversos eventos de resistência pela cidade. Susteve-se a mostra, finalizada dentro de seu cronograma e com o recorde anual de visitação na categoria - o risco indesejado por quem gesta polêmicas.

De volta ao extremo sul: em novembro do ano seguinte, 2018, a prefeitura da gaúcha Caxias do Sul decretou a suspenção das visitações escolares da rede municipal ao subsolo da sua Câmara de Vereadores, onde expunha-se Santificados, do caxiense Rafael Dambros, reassentando-se de seu cancelamento no Centro de Cultura Ordovás, meses antes. Composta de ressignificações iconográficas da santeria católica, dotadas de nudez e de certas alusões homoafetivas, o calvário

\footnotetext{
${ }^{4}$ KALIL, Alexandre apud SIQUARA, Carlos Andrei. Alexandre Kalil diz que obra de Moraleida é "absolutamente normal". Jornal O Tempo, Belo Horizonte, 10 out. 2017, não paginado. Disponível em: https://www.otempo.com.br/diversao/magazine/alexandre-kalil-diz-que-obra-demoraleida-e-absolutamente-normal-1.1529638 >. Acessado em: 07 dez. 2019.
} 
virtual do artista imputava-Ihe adjetivações tais quais a de criminoso e aberração, dentre as noticiáveis. A redarguição segue os protocolos das demais: a comunidade cultural local garante seu cronograma e acastela a arte e o artista, revezando-se com ele na vigia da mostra, em fiança da segurança das obras. Segue também as consequências: a exposição se elenca dentre as mais visitadas dos últimos anos na Câmara dos Vereadores de Caxias do Sul, listando em seu caderno de presenças a assinatura de Gaudêncio Fidelis, curador de Queermuseu. Em janeiro de 2019 aporta, com a grulhada já de praxe, no Espaço 900, na capital Porto Alegre - capital já se inscrevendo ela própria na praxe nacional da altercação expositiva, em feito e contrafeito ampliados pela maior dimensão urbana, e pela maior amplitude publicista que a acompanha.

Outra vez a São Paulo e a 2019 - Ano Internacional das Línguas Indígenas, conforme declarado pela ONU (Organização das Nações Unidas) e comemorado pela sua UNESCO (Organização das Nações Unidas para a Educação, Ciência e Cultura). No Centro Cultural Mestre Assis do município metropolitano mais vocacionado às artes e aos artistas, Embu das Artes - cuja perseverante classificação como 'aldeia' só foi substituída por 'freguesia' já em 1869 -, o dia dezesseis de julho relata uma invasão depredatória à $1^{\text {a }}$ Mostra Regional M'Bai de Artes Plásticas. Danificaram-se cerca de trinta cerâmicas e pinturas de artistas indígenas ali expostas (FIG. 1), como uma espécie de ato contra o vocativo local e contra os povos da região, e também como uma espécie de ápice a um cortejo de vandalismos e furtos de obras artísticas da cidade, que timbraram aquele mês. Ato contínuo, o registro de Boletim de Ocorrência, a abertura de inquérito e a alocação de efetivos de guarda patrimonial da prefeitura para atender o Centro Cultural. Efeito contínuo, a mostra seguiu até o final, e os expositores, de sete diferentes etnias indígenas, foram convidados a reapresentar as peças, mesmo e inclusive as danificadas, em uma galeria na região central paulistana.

Também ali, na região central de São Paulo, a Casa 1 - organização não governamental de voluntariado e fundo civis, centrada em acolhimento residente, clínicas diversas, esforço de empregabilidades e atividades educativas, artísticas, arte/educativas e culturais para a comunidade LGBTQIA+, particularmente em seu extrato vulnerável -, oportunizou a abertura de um forno popular na mesma área, debaixo do Viaduto Jaceguai, sob o qual e em cujas imediações estancia contingente populacional em situação de rua, já típico dos atináveis tetos públicos urbanos. Reeditados os desvalidos tempos, reeditou-se a obra Construcción de un horno popular para hacer pan, dos artistas argentinos Victor Grippo, Jorge Gamarra e A. Rossi, que ergueram um forno padeiro de barro em espaço aberto do centro de Buenos Aires, a praça Roberto Arlt, possibilitando compartilhar democraticamente sua bem-vinda 
Figura 1

Obras vandalizadas na exposição de arte indígena $1^{\mathrm{a}}$ Mostra M'Bai de Artes Plásticas, Centro Cultural Mestre Assis, Embu das Artes, 2019. Fotografia: Thiago Carvalho Wera'i, 2019. Fonte: pigmento.art.br

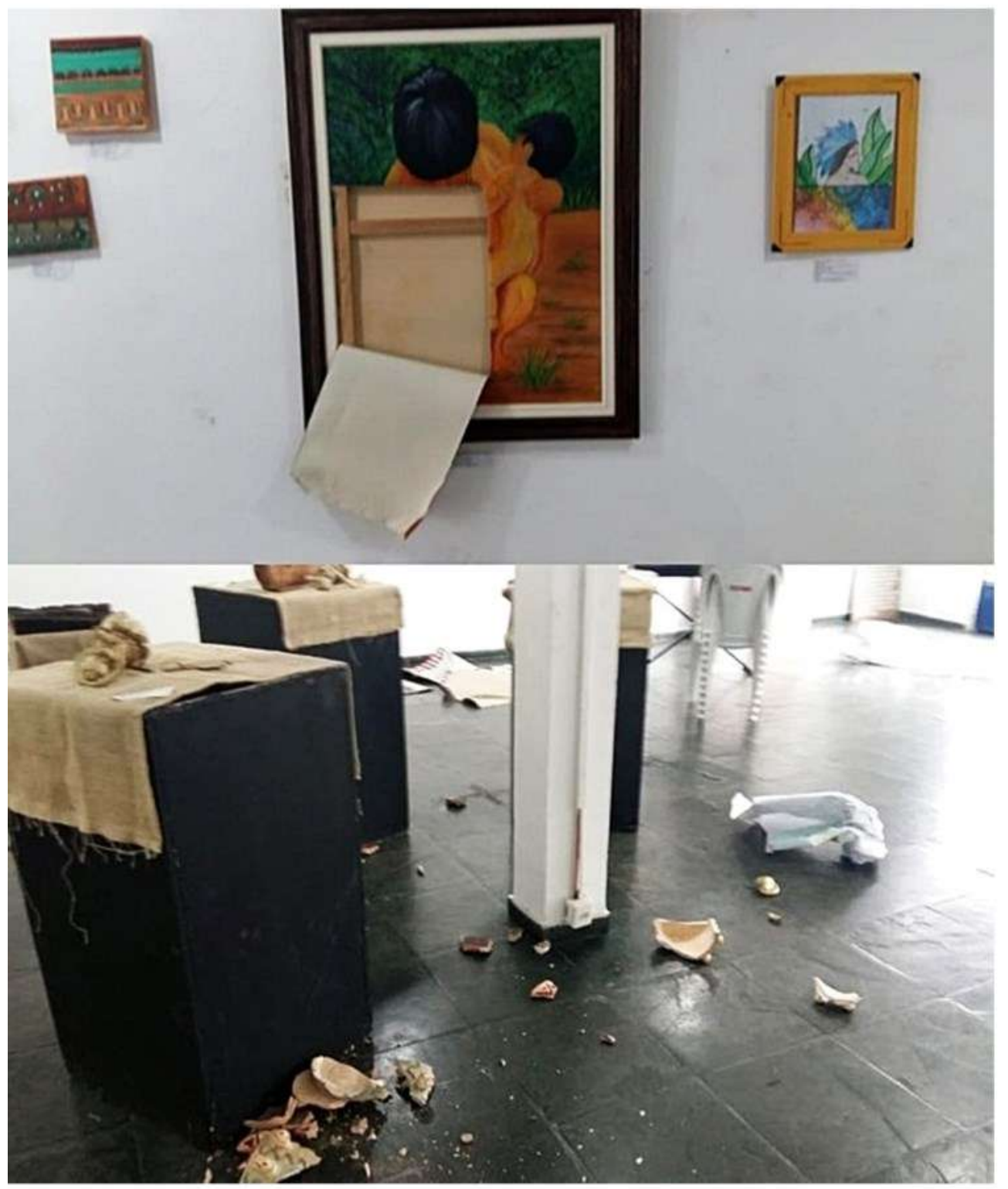

calefação de entorno, seu livre uso e suas panificações - e o diálogo que essa partilha conjunta promove -, sem reservas segmentárias, durante os aferrados expiros da ditadura argentina, em setembro de 1972. Desta feita nominada Forno Popular da Jaceguai, após três dias de construção e preparos a iniciativa teve sua abertura expositiva, e suas primeiras provedoras fornadas, programadas para o início da tarde do dia três de agosto de 2019. No mesmo dia, pela manhã, a instalação já fora totalmente erradicada pela prefeitura paulistana, não restando mais que os vestígios do barro no chão, donde se concluem as diferentes eficácias metodológicas dos diferentes arbítrios sátrapas, se comparada a aborção paulistana deste um aos poucos mas cabais dias portenhos de atividade daquele outro forno. 


\section{Dipolo}

A gangorra partidária ocidental, em seu capítulo mais recente, tem assistido ascender o pontal, a extremidade da sua polaridade ideológica que, claramente, demonstra não ter intenção ou interesse em portar consigo as artes. Não somente nega-se a levá-las no alteio de sua pá e pertencer-lhes sua ascese, como, mais ainda, intenta derrubá-las da prancha, justamente para mais e melhor garantir essa ascese. E mais e melhor delongar seu alto. Nada mais natural: as artes, por condição estrutural, tanto não se aceitariam portar quanto só a si se definem e completam no braço que agora descende. Digamos por condição estrutural, ao menos, as artes que honram a si, que cumprem a si. Digamos por condição estrutural, enfim, o conchego das artes no avesso e no inclinado.

Recusado e criminado nesse atual capítulo, então, o mundo expositivo ressente o desarrimo dos códigos protagonistas e se reorganiza no arrimo de si próprio, que lhe é confortável por traçado histórico. Há capítulos nos quais permanecer de pé já é - muito - resistir.

Tal vaivém de polos tende seu traçado ao imemorial, mas o extremismo sectário repete um cenário razoavelmente recente, e também profundamente marcado pelo dedo acusatório apontado para arte, cultura e demais desdobramentos da intelecção formativa e partilhada. Inscrito na década de 1980 e circunscrito principalmente entre seu início e meados da seguinte, quando uma pandemia - a então novidadeira AIDS - se deu de encontro às artes, afirmou condená-las e insinuou extingui-las, comparar tal cenário ao que agora se confirma e estabelece objetiva mensurar o quanto há de combatividade dentro da narração de si, pelo efeito engajador empático da exemplaridade.

Objetiva mensurar o quanto há de clamor, de falar alto, de autocapacitação da própria voz na arte contemporânea, que o há a partir da ruptura que a crise do HIV/AIDS, naquelas suas primeiras ondas de pânico e com aqueles seus tangíveis matizes de eugenia, fez observar e repercutir nas narrativas autorais daquele decênio em diante, quando um senso palpável de perda e de encurtamento - de vidas e de produções - dirigiu a arte à legitimação autogerida, sem poder esperar o aceite dos códigos políticos vigentes e impondo-se, urgente, através de todos os contextos midiáticos então tangíveis, de forma direta, ativa e ativista, mais do que tendo-os como um sistema de apoio e visibilidade ao acontecimento expositivo - seja apoio prévio, seja paralelo ou seja consequente. 
A urgência manifestante é a própria urgência expositora, tal e qual. A peroração e o combate à negligência médica e à recusa societária ataram essas duas pontas com aderência ainda maior que a do manifesto artístico, corporificaram a documentação obsessiva de si mesmo - em tempo real, enquanto houvesse tempo, frente à deterioração e à morte, expeditas ambas -, com suas doses espontâneas de ficção de si, superfetação e caracterização, doses colaborativas para a sintaxe. Reagiram as artes.

Reagiram, e as obras ainda sempre desencadeiam também no observador contemporâneo todas as questões que ele dirige à arte. $\mathrm{O}$ contexto, por sua vez, ganha cada vez mais interesse quanto mais ele se condensa na figura histórica da obra, seja em sua repressão seja em sua ideologização. Na costura entre 'arte e vida' foi liberada criatividade artística por todos os lados. ${ }^{5}$

A pandemia partida dali completa agora quatro décadas, e quatro décadas são uma vírgula para a história e para a narrativa historicista. $\mathrm{Na}$ recenticidade histórica da arte açulada pela crise HIV/AIDS funda-se e passa a valer o comportamento comunitário que virá a imperar nas redes sociais e nas relações digitais do novo milênio - publicização como condição de sobrevivência, personificação de si, editoração da própria vida, equalização de vozes e de grupos humanos. Se na arte contemporânea e na vida contemporânea os anúncios validam-se a si próprios pela fragmentação diretiva, pelas novas plataformas midiáticas e/ou expositivas, e mormente pela noção autobiográfica de identidade (sobrelevado pelas anteriores); na década de 1980 autorizaram-se pela identificação, pois a couraça e a pontaria daquela peste, naquele momento, dificilmente dissociaria tal empatia, a morte estava viva e postulando:

O nascimento da imagem está envolvido com a morte. Mas se a imagem [...] jorra dos túmulos é por recusar o nada e para prolongar a vida. As artes plásticas representam um terror domesticado [...]. Signo vem de séma, pedra tumular. ${ }^{6}$

${ }^{5}$ BELTING, Hans. O fim da história da arte - uma revisão dez anos depois. São Paulo: Cosac Naify, 2012, p. 280-281.

6 DEBRAY, Régis. Vida e morte da imagem: uma história do olhar no ocidente. Petrópolis: Vozes, 1993, p.20-24. 

Disso e mais que disso, a autonomia discursiva é conectada, ao mesmo tempo, como seria modelo, a forças maiores que o indivíduo (a tragédia, a pandemia) e conectada aos índices costumeiros da imanência biográfica na obra de arte, conectando-os entre si através da falência do corpo, quando:

É permitido pensar que a primeira experiência metafísica do animal humano, indissoluvelmente estética e religiosa, foi este perturbante enigma: o espetáculo de um indivíduo passando ao estado de anônima gelatina. ${ }^{8}$

Espetáculo que não somente coincide, mas sim perfeitamente adequa-se à espetacular América nortista, não como local de gênese, mas sim como de rebentação, de revelação e de anunciação do HIV/AIDS e de seus corolários - tendo em pauta a natureza midiática, de projeção de conteúdos de tal solo. Anunciação e revelação - substantivos estéticos e religiosos - em escopo de atributo (autobiográfico) e atribuição (fatídica) do artista condenado, que se sublima, se turgesce mais sadio e mais longevo, senão mais obsessivo, para a libido da arte que para a libido do sexo, pois "a libido só pode tomar a estrada da autossublimação como um fenômeno social: como uma força irreprimida, só pode promover a formação de cultura". 9 Para a castração involuntária, condicional e comunitária, aliando-se à autocastração voluntária, mais imperiosa que moral, que tal estado obriga, "a obsessão da AIDS desempenha sem dúvida um papel nesse exílio voluntário do sexo ainda que inexista nesse gênero de coisa relações de causa e efeito". ${ }^{10}$ Exílio que pauta a atemporalidade de um conteúdo que aponta o universo acusatório volteando sempre as (mesmas) motrizes sexuais, que dotam um núcleo e uma prenhez a essas tão diversas situações expositivas recentes.

\section{Estudo de caso}

A mostra HIDE/SEEK: Difference and Desire in American Portraiture, teve sua primeira montagem, em dezembro de 2010, organizada pela e

\footnotetext{
8 DEBRAY, op. cit., p.29.

${ }_{9}^{9}$ MARCUSE, Herbert. Eros e civilização - uma interpretação filosófica do pensamento de Freud. Rio de Janeiro: LTC, 1999, p.182.

10 BAUDRILLARD, Jean. Tela total: mito-ironias da era do virtual e da imagem. Porto Alegre: Sulinas, 1997, p. 83-84.
} 
exibida na Smithsonian National Portrait Gallery, na capital estadunidense Washington, com cocuradoria de David C. Ward, historiador sênior emérito da instituição, e de Jonathan D. Katz, diretor do Programa de Doutorado em Artes Visuais da filial da cidade de Buffalo da State University of New York. Tematizou ideários de gênero e sexualidade na arte do retrato norte-americano, explorando imagerias produzidas sobre a homossexualidade, e/ou pela autoria que se aloja voluntariamente nesta orientação. Necessariamente, expandiu as figurações identitárias ao abraçar as respostas artísticas aos levantes de Stonewall (marco espetacular de escalas outras, diga-se) e ao início da epidemia de AIDS, destacando promover o evento com uma paradigmal entrevista de Larry Kramer a Katz.

Uma das figuras mais emblemáticas da década perdida, Kramer, que jamais se contaminou (surpreendentemente, segundo o próprio), hoje octogenário, foi advogado especialista em saúde pública, dramaturgo, ensaísta, ativista LGBTQIA+ - quando tal sigla sequer alcançava o acrônimo GLS (Gays, Lésbicas e Simpatizantes) -, e pedra de toque da luta pelos soropositivos e aidéticos, desde o início da pandemia. Cofundou o GMHC (Gay Men's Health Crisis), que acabou se tornando a mais ampla organização privada de representação e assistência aos enfermos daquele momento crítico, anterior ao batismo do hoje amplo e popular cunho ONG, atuando com conexão direta à produção artística do período, e cujas ações públicas buscavam forçar atitudes legislativas protecionistas e dar visibilidade à situação dos enfermos, contraposta à inação governamental. Visibilidade essa que se apoiava justamente na produção e nos produtores de arte, atraídos pela solidariedade e pelo pertencimento cognoscível. Uma nação tão pautada pelo culto à celebridade aprendeu cedo a recorrer aos indivíduos que a esta emblemam, em prol da atenção às causas específicas, que em contraparte dotam nobreza e altruísmo a essas figuras.

Aprendeu também a recorrer, no mesmo excerto, aos eventos de gala que angariam fundos, uma prática bastante estadunidense com a qual a GMHC se provém ainda hoje, quando permanece operante, agora mais direcionada a aconselhamento jurídico, encaminhamento profissional, acompanhamento médico e albergaria para os ainda muitos sorológicos desprovidos, especialmente os em profissão de risco e situação de rua. A somarem-se as exposições e as ações educativas e arte/educativas, a GMHC modela e enrama herdeiros institutivos tais quais a supramencionada Casa 1 - outra gênese oitentista.

No crescimento da entidade - e no consequente crescimento de seus poderes de voz, trânsito e barganha com as classes políticas, 
farmacêuticas e comunitárias - gestaram-se as habituais divergências internas, que caçam bruxas. O torque político de tal engrenagem tachou as ações de Kramer como excessivamente obstinadas, severas e radicais, enquanto vestidas dessa voz, desse trânsito e dessa barganha (embora vestidas, por debaixo, da urgência das fatalidades). Acusou-as de pouco ou nada contemporizadoras, tolerantes, arqueáveis para seu próprio benefício, ainda que por trás de tais arqueios houvessem vidas. Considerou-as desprovidas, portanto, das malícias da administração política fundamental - tal espécie de desprovimento é mais outra postura que renasce nos extremismos de agora.

Apostando na emergência circunstancial, Kramer então se desliga da GMHC para cofundar a hoje mítica Aids Coalition to Unleash Power, de hoje ainda mais mítico acrônimo Act Up, que irradiou sua guerrilha pacífica em células semi-independentes em diversas cidades do mundo, rastreando questionar a rejeição social vigente, exortar a pesquisa farmacêutica hábil e democratizar o acesso à profilaxia e à medicina paliativa. Singularizadas, em suas estampas, pelo nome da cidade abaixo da sigla, algumas dessas células ainda permanecem em atividade, também sustentando mostras de arte e similares atividades distintivas.

Muitas das políticas públicas, atualmente em voga e plena validade, ali se fundaram ou se revisaram, e devem crédito a Kramer. Seu testemunho da eclosão do contágio e das ações contundentes do GMHC se registram em sua premiada peça teatral autobiográfica The Normal Heart, que estreou em Nova lorque em 1985, cujo conteúdo em nada exaure suas rotineiras palestras e a entrevista para a exposição HIDE/SEEK supradita, que também destacou apresentar obras renomadas de Keith Haring, Robert Mappelthorpe, Robert Gober, Andy Warhol, David Hockney, David Wojnarowicz, A. A. Bronson, Félix Gonzales-Torres e Annie Leibovitz, entre outros.

Ativistas autointitulados cristãos (outra recorrência contemporaneamente atualizada) e membros do Congresso norteamericano (mais outra) pressionaram o Smithsonian Institute, que superintende o espaço, e tiveram acatada essa pressão (ainda outra) para excluir do corpo expositivo o vídeo A fire in my belly, obra de 1987 de Wojnarowicz, por retratar, em meros onze segundos de seus quadros, formigas vivas rastejando sobre o corpo crucificado de Jesus Cristo, representado numa pequena peça decorativa kitsch (FIG. 3).

A mostra acabou sendo reorganizada um ano depois - com a peça reincluída -, através da parceria entre o novaiorquino Brooklyn Museum e o Tacoma Art Museum, também de Washington, com projeto 
Figura 3

David Wojnarowicz, A fire in my belly, 1987.

Fotograma de filme

Super8mm, mudo, $13^{\prime} 6^{\prime \prime}$, MoMA, Nova lorque. Fonte: Youtube

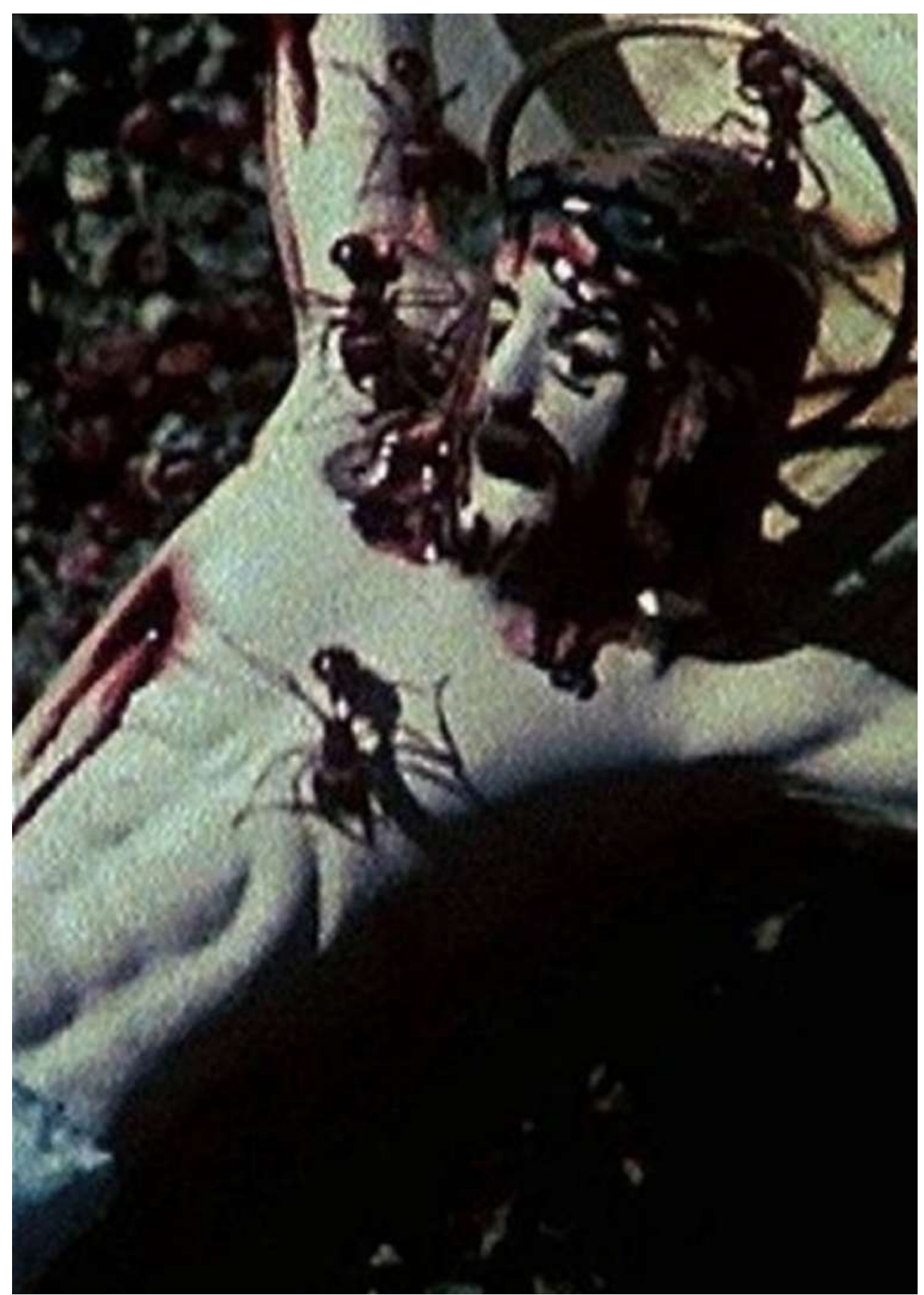

curatorial de Tricia Laughlin Bloom, para sua reapresentação sequencial nestes dois espaços, ante a recusa à reinstalação do vídeo na primeira montagem, que foi arguida pela contraparte investidora e pela comunitária (mais um bis temporal).

Da arguição, a Andy Warhol Foundation ameaçara o instituto com a retirada de futuros fundos, e o canadense Bronson reivindicara à National Gallery of Canada, enquanto proprietária, que em solidariedade 
retirasse sua obra da exibição: a pungente fotografia intitulada Felix Partz, June 51994 (FIG. 4), que retrata o cadáver de seu parceiro de arte e de casamento a três, Felix Partz, com os olhos abertos e vítreos mirados na objetiva, estiolado em vestes que então lhe folgam assustadoramente, recostado na cama apenas alguns minutos após sua morte em decorrência da AIDS pouco amparada, então pouco amparável. Uma das imagens mais fortes e representativas do período, descrita costumeiramente como angustiante, quase insuportável de se observar - sentimento que seu tamanho mural só faz amplificar. Definitivamente bem mais insuportável à visão do que a peça de Wojnarowicz, donde se receia quais convicções fazem um cidadão que se entende religioso (na semântica constando-se solidário e empático) inquietar-se mais com pequenos insetos andejando sobre um pequeno crucifixo de plástico, e menos com a imagem de um seu igual emaciado e morto em desassistência (a atualidade também mantém essa ambivalência de critérios). Bronson explicita em mensagem eletrônica ao diretor do museu:

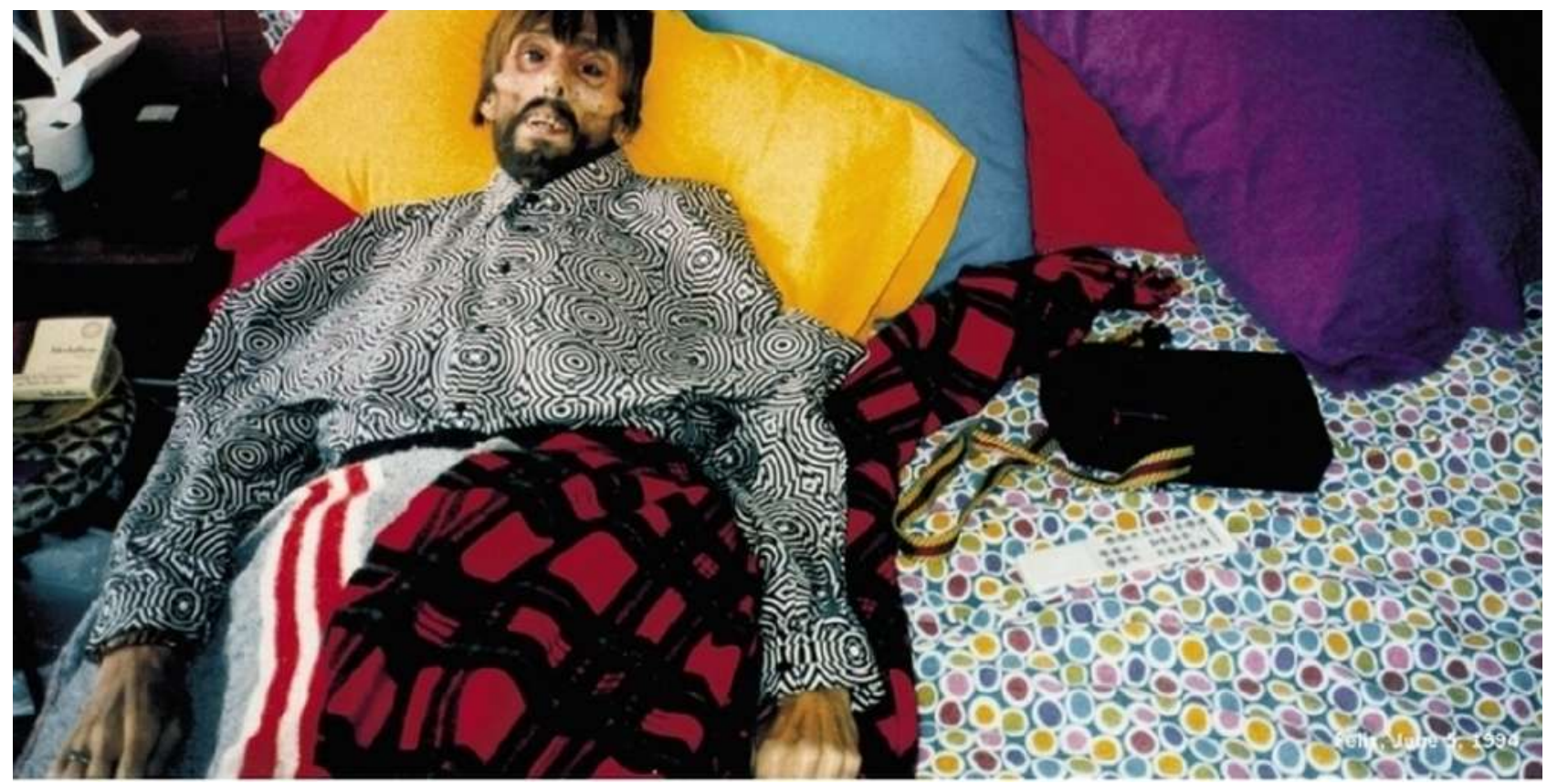

Figura 4 Prezado Martin Sullivan, eu enviei e-mail para a National Gallery of Canada A. A. Bronson, Felix Partz solicitando que removessem minha obra 'Felix Partz, June 5, 1994' da exposição 'Hide/Seek' na National Portrait Gallery. Resisti a dar esse passo, esperando que algum acordo pudesse ser realizado em relação à censura do vídeo de David Wojnarowicz, mas está claro que isso não acontecerá tão cedo. Como um artista que assistiu em primeira mão a tremenda agonia e dor que vivenciaram tantos da minha geração, e com as quais morreram, eu não posso aceitar a decisão do Smithsonian serenamente. Editar a história homossexual dessa maneira é doloroso smitshsonianmag.com $213,4 \times 426,7 \mathrm{~cm}$, National Gallery of Canada, Ottawa. Fonte: listart.mit.edu Arts Center, Cincinnati, EUA.

Fonte: 
desrespeitoso. Atenciosamente, A. A. Bronson - Diretor Artístico do Instituto de Arte, Religião e Justiça Social no Seminário Teológico da União 11

A polêmica de HIDE/SEEK para com a obra de Wojnarowicz repete, ela própria, uma longa trajetória de discursos ideológicos, que acompanha o vídeo em particular e o corpo da obra do artista em geral, senão seu próprio sujeito, mas que é visivelmente crescente com o passar dos anos: se no biênio de sua produção, encerrado em sua exibição, acomodou-se socialmente como uma obra de arte rematada e em pleno direito de sêla; a roda do tempo, se não temretrocedido a tradicionalismos belicistas, de fato não os derrotou como sugeria tê-lo feito, ao contrário, demonstra acalentar e aquecer a gestação dos confrontos, uma surpresa pouco indiciada, outro pasmo histórico.

Desses confrontos, a atualidade os pare: o drama do idiota da aldeia promovido a portador da verdade pela equalização digital das vozes e das autoridades de argumento, como preconizara Umberto Eco em seu antológico discurso na Universidade de Turim, por ocasião do recebimento de seu título de Doutor Honoris Causa. ${ }^{12}$ As vozes arrogam-se subir decibéis como estratégia de convencimento e subjugação. São agora gritos.

O primeiro protesto veio de Bill Donahue, o chefe da Liga Católica, que alegou que A Fire in My Belly foi 'projetado para insultar e infligir injúria e agressão às sensibilidades dos cristãos' e decretou a obra

11 BRONSON, A. A. apud GOPNIK, Blake. Artist asks to withdraw work from 'Hide/Seek' exhibit to protest video removal. Washington Post, Washington, 16 dez. 2010, não paginado. Disponível em: < http://voices.washingtonpost.com/artspost/2010/12/artist_asks_to_withdraw_work_f.html >. Acessado em: 22 nov. 2018. No original: "Dear Martin Sullivan, I have sent an email to the National Gallery of Canada requesting that they remove my work 'Felix Partz, June 5, 1994' from the 'Hide/Seek' exhibition at the National Portrait Gallery. I had resisted taking this step, hoping that some reconciliation could be reached regarding the censorship of the David Wojnarowicz video, but it is clear that this is not coming any time soon. As an artist who saw first hand the tremendous agony and pain that so many of my generation lived through, and died with, I cannot take the decision of the Smithsonian lightly. To edit queer history in this way is hurtful and disrespectful. Yours truly, A A Bronson - Artistic Director Institute of Art, Religion, and Social Justice at Union Theological Seminary" (tradução nossa).

12 Cf. ECO, Umberto apud ARENA, Fabio. Laurea honoris causa in "comunicazione e culture dei media". Radio Radicale, Torino, 10 jul. 2015, não paginado. Disponível em: < http://ultrarradicalismo/scheda/444639/laurea-honoris-causa-in-comunicazione-eculture-dei-media-ad-umberto-eco >. Acessado em: 04 dez. 2019. 
como 'discurso de ódio', especialmente durante a temporada de Natal. As similaridades entre a retórica de Donahue e os argumentos contra a exibição, em 1989, da obra Piss Christ, de Andres Serrano, uma fotografia de um crucifixo de plástico mergulhado num líquido amarelo (possivelmente a urina do artista), são inegáveis. Em 1989, a controvérsia sobre a suposta blasfêmia da imagem de Serrano, estimulada por Wildmon, Helms e D'Amato, afetou as políticas públicas, as gestões museológicas das temáticas controversas e, é claro, os fundos federais. Ao contrário do caso de Serrano, os detratores de Wojnarowicz não puderam afetar sua carreira: Wojnarowicz faleceu de AIDS em 1992, aos trinta e sete anos de idade. ${ }^{13}$

Nesse defeso, Moraleida (suicida aos precoces vinte e dois anos de idade) está em excelente companhia. Nessa defesa, as retaliações de Bronson e da Andy Warhol Foundation, da mesma forma que certas manobras resolutas de algumas instituições de arte brasileiras (não obstante certas ductilidades de outras), e também tantas mobilizações de categoria e de populares brasileiros, amadureceram e amadurecem formatos de resistência e modelos de antinomia, que ainda adernam nalguns momentos em razão de seus próprios e continuados processos de decantação.

\section{Ortos}

Além dos agora impreteríveis partidarismos de Independência em risco e Quem não luta tá morto, e além das agora improteláveis inclusões da $1^{a}$ Mostra Regional M'Bai de Artes Plásticas e Forno Popular da Jaceguai, o inventário aqui introduzido de altercações expositivas brasileiras recentes é uma amostra representativa de tantas outras colisões de

13 TYBURCZY, Jennifer. Sex museums: the politics and performance of display. Chicago: University of Chicago Press, 2016, p. 13. No original: "The first outcry came from Bill Donahue, the head of the Catholic League, who claimed that A Fire in My Belly was 'designed to insult and inflict injury and assault the sensibilities of Christians' and declared the artwork 'hate speech', especially during the Christmas season. The similarities between Donahue's rhetoric and arguments against the 1989 display of Andres Serrano's Piss Christ, a photograph of a plastic crucifix submerged in a yellow liquid (possibly the artist's urine), are undeniable. In 1989, the controversy over the alleged blasphemy of Serrano's image spurred by Wildmon, Helms, and D'Amato affected public policy, museum management of controversial subject matter, and, of course, federal founding. Unlike the case of Serrano, Wojnarowicz's detractors could not affect his career: Wojnarowicz died of AIDS in 1992 at the age of thirty-seven" (tradução nossa). 
pensamento suscitadas pelo acontecimento expositivo, é um indício do andamento dos convívios sociais, é um sintoma das condutas coletivas que centra e emparelha, com maior recorrência, as apostas de seus aceites e os princípios de suas recusas na diversidade de vidas e vivências que essas exposições publicam. Os aceites centram tal diversidade na exibição pública do exercício da sexualidade e do desejo, e as recusas a ombreiam no exercício da religiosidade. No centro e no ombreamento de diversidade e religiosidade, por sua vez, fixam-se corpo, gênero e orientação. HIDE/SEEK regressa um decênio, para amostrar o mesmo: corpo e gênero historicamente reprisados no núcleo das angústias sociais. Daí o orto da dupla recusa aos aidéticos oitentistas: a doença Ihes recusa a vida, a sociedade os recusa a equidade. Daí se faz necessário regressar mais dois decênios.

Em que pese a atemporalidade das repulsas morais ao corpo, ao gênero, à diversidade e à exteriorização expositiva destes - atestada, por exemplo, no abalo da pintura realista de Gustave Coubert, L'Origine du monde, de 1866, ou nas outorgas nazistas de uma tal 'arte degenerada', moderna e abominada, contraposta a uma tal 'arte oficial', romântica e virtuosa - a alvorada da vigente amálgama entre o corpo exposto, o gênero equiparado, a orientação avultada, o fator favorecedor das polêmicas e a autonomia discursiva se compõe e alicerça na década de 1980 , com sua riqueza aquisitiva yuppie e sua raivosa letra escarlate para a AIDS. Presente em HIDE/SEEK, a sombra e as decisões estéticas de Mappelthorpe aquilatam, bem ali no fim daquela década, o ensejo histórico que circuitou todos esses constitutivos pra dali em diante, formatando essas guerras culturais como as temos até hoje. Falecido em março de 1989, na mesma decorrência da AIDS que ceifou Wojnarowicz, sua individual póstuma que abre a década seguinte, The perfect moment, inaugurada em abril de 1990, baliza os padrões que a sucedem até hoje, tanto em termos de pavios expositivos quanto em termos de mobilizações, diligentes em ditar quais podem e quais não podem ser os conteúdos da arte - batalha perdida.

A mostra - que já havia sido cancelada estando já montada, ainda em 1989, na Corcoran Gallery of Art da mesma Washington de HIDE/SEEK - abriu no CAC (Contemporary Arts Center) de Cincinnati, centro-oeste estadunidense, contendo cento e vinte e cinco fotografias de Mapplethorpe, sempre envoltas em um profundo estudo de luz, contando com suas já inconfundíveis flores (extraídas da série Portfolio $Y$ ) e suas clássicas nudezes masculinas, dadas ao corpo negro pouco habituado ao palco da arte ocidental (frações da série Portfolio $Z$ ). Dentre as peças, dois retratos de nudez infantil, que dão o lastro de pedofilia ao qual invariavelmente recorrem os ofendidos da arte, e cinco 
Figura 5

Protestos em apoio à exposição The Perfect Moment, de Robert Mapplethorpe, em Cincinnati, 1990.

Fotografia: John

Stamstad.

Contemporary Arts

Center, Cincinnati, EUA.

Fonte:

smitshsonianmag.com registros explícitos da cultura sadomasoquista homossexual vigente, de menor (ou nenhum) arcabouço simbólico comunal - fragmentos do conjunto intitulado pelo artista como Portfolio $X$, composto de fetiches explícitos registrados in loco.

Por essas sete imagens, a conservadora Cincinnati se viu na medula das contendas rueiras entre, de um lado, grupos religiosos, grupos tradicionalistas e grupos inomináveis - com direito a literais saudações nazistas às portas do julgamento - e, do outro (FIG. 5), apreciadores de arte, artistas, populares e o jovem movimento LGBTQIA+, que mais edificava seu agrupamento e seus passos, e que acorreu à defesa manifestante. As sete fotografias alavancaram uma ação penal por obscenidade, partida da promotoria de Hamilton County (Condado que Cincinnati sedia), e direcionada ao diretor do espaço, Dennis Barrie, elencando também o museu em si como réu - a primeira vez na história estadunidense em que uma acusação criminal direcionava se a este tipo de instituição, receptáculo historicamente encouraçado pela própria força da transmissão de seus saberes.

A comoção potencializou-se nacionalmente e, como La Bête, alcançou até mesmo o Senado, onde mandatários conservadores forçavam sua pejoração associativa das imagens à orientação sexual de Mapplethorpe, atrelada na pejoração associativa de sua orientação à causa de sua

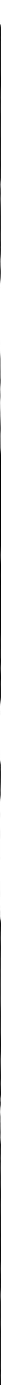


morte. Outra batalha perdida: pautar coletivamente o que é e o que não é pornografia, e o que a separa da arte - significados que se individualizam entre sistemas de experiência, associação, memória, juízo e cognição. Uma ganha: apurações de institutos de pesquisa anunciavam uma clara maioria nacional apostando na importância de exposições dessa natureza, a despeito do desafio que possam representar para certos percentuais populacionais.

A despeito do dia seguinte, em cuja madrugada se deu o veredito unânime, foi o dia do julgamento, vinte e cinco de setembro, o informalmente eleito, por muitos e até hoje, como 'Dia da Arte'. O júri de oito pessoas decidiu pela inocência dos acusados - ou mais: pela inocência da arte. Um valoroso precedente foi aberto para a autonomia e para a perpetuidade dos cubos brancos, mesmo que permaneçam assíduos das berlindas e cheguem a fazer supor o colapso de suas certezas, como ora bem se observa. E a obra de Mapplethorpe se inscreveu em definitivo no tabuleiro histórico das artes.

Os anos 60 e 70 viram a fotografia de nu masculino sair da gaveta. Nos anos 80, ela havia de estar na boca-de-cena. Na euforia dos anos 80, gastava-se sem conta, nomeadamente no domínio da arte. Os novos-ricos queriam investir o seu dinheiro em qualquer coisa que se visse e mostrar que eles (e as suas mulheres) tinham gosto. Robert Mapplethorpe estava pronto e esperava por eles. Protegido de Sam Wagstaff, rico colecionador de fotografias, Mapplethorpe foi habilmente promovido a criador de um novo gênero de fotografias de arte que se vendiam caro. A sua obra incluía lindas crianças, elegantes damas da alta-roda, flores delicadas e homens nus de físico impressionante, bem servidos de órgãos sexuais. Por vezes, ele só fotografava o órgão em questão, em grande plano. A sua técnica estilizada, muito adaptada aos retratos de crianças e às flores, tornava estas imagens de sexos ainda mais chocantes e este choque foi o detonador. A fotografia de arte, que andava à procura do seu caminho, acabava de o encontrar no nu masculino. Quando a cidade de Cincinnati se recusou a mostrar os nus de Mapplethorpe no seu museu, o fotógrafo tornou-se numa celebridade mundial. Desde então, mostrar nus masculinos equivalia a defender a liberdade de expressão artística. Em pouco tempo, não houve exposição de 
fotografia que não tivesse os seus nus ousados. Mapplethorpe não escondia a sua homossexualidade, o que incitou muitos fotógrafos de nu a tornar pública a sua sem que isso provocasse escândalo. ${ }^{14}$

Com a ventura da notoriedade (outro preceito para a contemporaneidade) instantânea de um momento tão decisivo, as fotografias de Mapplethorpe ajudaram a inscrever no direito da arte a exposição extrema do corpo e a legitimação plástica da negritude. Também ensaiaram inscrições de equanimidade para gênero e para orientação, que se direcionaram também à sua própria figura, computando assim a narrativa de si - crescente dali em diante e, pelo atestado dos recentes cubos brancos e das recentes redes sociais, aparentemente ainda não totalmente avizinhada de seu cume.

Interprete-se disso o dado epistemológico do objeto artístico enquanto responsivo à circunscrição, ao enclave do seu sujeito autoral (e simultaneamente ao território dúbio entre um e outro, objeto e sujeito) não apenas ao tempo e lugar de valência, de continência - e de morte de ambos, mas também a uma miríade de determinantes e vicissitudes, estabelecidos ou intuídos por esse tempo e por esse lugar, tais quais os cenários circunscritores: sociais, culturais, econômicos, partidários, raciais - especialmente as fronteiras naturalmente oscilantes entre uns e outros e entre todos. A mobilidade desses cenários, e portanto daquele enclave, tem por paradoxo a necessidade de sua própria existência, referenciada temporal e geograficamente - a precipitar etnografias e alteridade na arte.

Não que essa circunscrição expresse encerramento, especialmente no que se refere ao espaço - nativo ou adotivo -, mas também no que se refere ao tempo, cuja leitura é móbil e "supõe também uma crítica em regra da noção de evolução, tal como a história da arte a emprega espontaneamente". ${ }^{15} \mathrm{E}$ não que expresse pertencimento, pois a "premissa não é que a arte e a teoria refletem algum momento socioeconômico, mas, antes, que são marcadas por suas contradições, e que, portanto, $[. .$.$] possuem uma historicidade". { }^{16}$

${ }^{14}$ LEDDICK, David (Ed.). The male nude. Colônia: Taschen, 2005, p. 396.

15 DIDI-HUBERMAN, Georges. Diante do tempo: história da arte e anacronismo das imagens. Belo Horizonte: UFMG, 2015, p.195.

16 FOSTER, Hal. O retorno do real. São Paulo: Ubu, 2017, p 81. 
Afinal, da arte a história tende a legitimar discursos posto os discursos a legitimarem, quando seleciona-os nesta mutuação reciprocamente referente, bem como:

Tipicamente genealógica, capaz de interrogar-se, ao mesmo tempo, sobre as condições de engendramento das obras e sobre o ritmo agonístico de suas destruições, de suas sobrevivências, de [...] suas revoluções ou insurreições em todos os gêneros. ${ }^{17}$

Afinal, da arte, em respeito a si, não se deve encenar tragédia sem honrar Dionísio.

Recebido: 15 de dezembro de 2019; Aceito: 16 de março de 2020

Este é um artigo publicado em acesso aberto sob uma licença Creative Commons (cc)

17 DIDI-HUBERMAN, op. cit., p.195. 